\title{
LUT
}

Lappeenranta

University of Technology

\section{Dissolution of sodium, aluminum and caustic compounds from bauxite residues}

\author{
Kinnarinen Teemu, Holliday Lloyd, Häkkinen Antti
}

This is a Final draft version of a publication

published by Elsevier

in Minerals Engineering

DOI: $10.1016 /$ j.mineng.2015.06.007

Copyright of the original publication: (c) Elsevier 2015

Please cite the publication as follows:

Kinnarinen, T., Holliday, L., Häkkinen, A., Dissolution of sodium, aluminum and caustic compounds from bauxite residues, Minerals Engineering, 2015, 79: 143-151. DOI: 10.1016/j. mineng.2015.06.007 


\title{
Dissolution of sodium, aluminum and caustic compounds from bauxite residues
}

\author{
Teemu Kinnarinen ${ }^{1 *}$, Lloyd Holliday ${ }^{2}$, Antti Häkkinen ${ }^{1}$ \\ ${ }^{1}$ LUT Chemistry, Lappeenranta University of Technology, P.O. Box 20, FI-53851 Lappeenranta, Finland \\ ${ }^{2}$ Outotec (Filters) Oy, 8 Winchilsea Ave, Newark, United Kingdom \\ ${ }^{*}$ Corresponding author Tel.: +358 40 5621398, E-mail: teemu.kinnarinen@lut.fi
}

\begin{abstract}
Bauxite residues consist of solid particles and a strongly alkaline liquid. Depending on the selected disposal method, the solids content of washed bauxite residues varies from 30 to $70 \mathrm{w}-\%$. The objective of this study is to provide better understanding of the leaching of metals and caustic compounds from bauxite residues. These issues are receiving more attention in the alumina industry, not only due to the need to recover the valuable compounds more effectively, but also due to the environmental impacts caused by leaching of soluble metals and alkali from bauxite residue disposal areas. Three different bauxite residues of industrial origin were investigated by straightforward leaching and dilution methods by using water as the diluent. In the analysis stage, dilution with a nitric acid solution was also tested. The main dissolved compounds were analyzed with atomic absorption spectroscopy and thermometric titration. The results showed that the sodium balance was influenced by the applied L/S ratio, which implies that the solid particles were partially dissolved. Comparison of the dissolution behavior of sodium, aluminum and total caustic (i.e. the hydroxyl ion content) revealed changes in the $\mathrm{Al} / \mathrm{Na}$ and Caustic/ $\mathrm{Na}$ ratios, which deserve to be studied further in the future. Grinding the particles did not increase the liberation of sodium from the solids, i.e. the role of captured sodium did not seem to be important.
\end{abstract}

\section{Introduction}

The production of alumina from bauxite ore by the Bayer process generates large quantities of highly alkaline waste called bauxite residue, which is of serious environmental concern. The desanded bauxite residue is separated from the sodium aluminate liquid by a series of gravity thickeners with polymer addition to increase the settling velocity (Kirwan, 2009; Sidrak, 1997). These thickeners are typically operated according to the counter-current principle (Pejcinovic et al., 2007), in order to minimize the loss of alkali and aluminate with the bauxite residue. The composition of the bauxite residue depends on many factors, such as the quality of the bauxite ore and the Bayer process parameters (Jankovic et al., 2013; Mayes et al., 2011; Zhang et al., 2009).

It is estimated that approximately 120 million tons of bauxite residue are produced in the world annually (Milacic et al., 2012; Power et al., 2011; Rubinos and Barral, 2013). Thus it is evident that bauxite residue is currently a major concern in the production of alumina (Liu et al., 2013). The disposal methods of bauxite residue have improved greatly during the last decades. The disposal of the slurry into the marine environment has practically ended, wet stacking in large 
ponds is still applied, and dry disposal methods have gained popularity (Boger, 2012; Cooling, 2007; Fourie, 2009; Green and Boger, 1997; Jones and Boger, 2012; Nguyen and Boger, 1998). Dry stacking methods are currently the recommended practices for the disposal of bauxite residues (Kirwan et al., 2013; Hind et al., 1999). In spite of the benefits of dry stacking, leaching of harmful compounds from the disposed residue remains a challenge which can be partially resolved by washing the bauxite residue carefully prior to disposal. Understanding of the dissolution phenomena should therefore be increased.

A number of different utilization methods for bauxite residues have been proposed. The most potential applications are the use as construction material (Samal et al., 2013; Pontikes and Angelopoulos, 2013), ceramic materials (He et al., 2012), and various water treatment applications (Atun and Hisarli, 2000; Liu et al., 2009; Poulin et al., 2008). In these cases, neutralization of the residue is typically required to make it more compatible with the environment (Wang et al., 2008; Agatzini-Leonardou et al., 2008). The recovery of valuable compounds, such as metal oxides, has also been considered (Brunori et al., 2005). Although bauxite residues seem to be potentially applicable for many purposes, their utilization has not become commercially significant (Clifton et al., 2007; Lee and Pandey, 2012). The neutralization can be performed with seawater (Johnston et al., 2010), $\mathrm{CO}_{2}$ (Sahu et al., 2010; Bonenfant et al., 2008; Dilmore et al., 2008), or various acidic salts (Hamdy and Williams, 2001).

It has been observed that harmful components may also leach from bauxite residues. In addition to alkaline compounds such as $\mathrm{NaOH}$ (Liu et al., 2007), the leaching of heavy metals, such as $\mathrm{Cr}$, $\mathrm{Cu}, \mathrm{Ni}$, and $\mathrm{Pb}$, can cause problems (Ghosh et al., 2011; Rubinos and Barral, 2013), although the leachable alkali may be of a greater concern in some cases (Kutle et al., 2004). The removal of (heavy) metals can be carried out by chemical or biological leaching methods (Qu et al., 2013; Vachon et al., 1994). Leaching of alkalinity from the stock may continue for a long time, which makes it important to collect and treat the leachate properly (Kirwan et al., 2013).

The caustic compounds which are to be recovered as effectively as possible, are present either in the mother liquor or in the bauxite residue solids, desilication products in particular (Thornber and Binet, 1999). The recovery of the valuable caustic and dissolved aluminum compounds can be performed by dewatering and washing the bauxite residue in various filter units (Arslan et al., 2012; Borges et al., 2011; Kinnarinen et al., 2012). The main motivation for the present study comes from a previous pressure filtration study of the authors (Kinnarinen et al., 2013) and analytical procedures performed for two other studies (Kinnarinen et al., 2015; Kinnarinen et al., 2012), where it was observed that the total amount of sodium and aluminum removed from bauxite residue solids is significantly affected by the applied pressure difference, temperature, and wash ratio. On the basis of mass balances, it was clear that also the so called insoluble solids were partially dissolved in the process. This observation could be explained by liberation of soluble sodium from the pores of the particle flocs, dissolution of particles due to the reduction of the $\mathrm{pH}$, and simply by changes in the tendency of the investigated compounds to remain adsorbed on the surfaces of the particles. The importance of these phenomena can be investigated by breaking down the particle flocs by mechanical shear and by dilution of the bauxite residue slurry with pure water. 
The main objective of this study was to evaluate the dissolution of different bauxite residue solids by diluting the slurry with water to see how the dissolution is affected by the dilution ratio. This evaluation was primarily based on the concentration of dissolved sodium, but also on the concentrations of dissolved aluminum and total caustic and total soda as defined below in Section 2.3. The original and diluted bauxite residue samples were ground in a planetary ball mill to investigate the role of breakage of particle flocs in the dissolution of sodium from the solids. On one hand, the dissolution phenomena were evaluated with respect to the particle size distribution of solids, and on the other hand, in relation to the abovementioned dissolved compounds in the liquid phase. Atomic absorption spectroscopy and thermometric titration were applied for the analysis of the dissolved compounds. The results of this study help to understand the importance of appropriate washing of bauxite residue prior to disposal, and to illustrate the risks resulting from improper stacking of the residue.

\section{Materials and methods}

\subsection{Characteristics of the slurries}

Three bauxite residue slurries obtained from industrial alumina production sites were investigated. In this paper, the slurries are called Slurry I, Slurry II, and Slurry III. The slurries were obtained from different origins in three continents. All the slurry samples were taken from the underflow of the last wash thickener of the residue washing train. The slurry samples were pumped in air-tight plastic barrels, which were then stored at ambient temperature during transportation to the laboratory. The slurries were homogenized again in a baffled mixing tank equipped with a pitchedblade turbine and a recirculation pump. Small samples for the experiments were taken from the recirculation pipeline after several hours of mixing.

The caustic content of the slurries was relatively high, as the $\mathrm{pH}$ values shown in Table 1 indicate. Some other essential characteristics of the slurries are also presented in Table 1. The methods of analysis are described below.

The $\mathrm{pH}$ values of the slurries were measured from supernatants of clarified samples with a WTW pH 340i pH meter and WTW SenTix 41 electrode. The total solids contents (TS) of the slurries were measured by drying the slurry samples at $105{ }^{\circ} \mathrm{C}$ to dryness. The total dissolved solids contents (TDS) were measured by drying clear filtrate samples obtained by filtering the slurries through Whatman \#42 filter paper at $180{ }^{\circ} \mathrm{C}$ to dryness. The density of each slurry was measured simply by measuring the mass of the sample with a certain volume in a graduated cylinder. The procedures of TS and TDS measurement were repeated twice and the averages were calculated.

The sodium concentrations $\mathrm{C}_{\mathrm{Na}}$ were measured with atomic absorption spectroscopy (AAS) by using a Thermo Scientific iCE 3000 atomic absorption spectrometer. To prepare a sample for a standard $\mathrm{Na}$ analysis, the slurry sample was centrifuged, and the clear supernatant was filtered through a syringe filter with a nominal pore size of $0.2 \mu \mathrm{m}$. Another analysis procedure was also used in order to examine how much sodium is dissolved when the sample is diluted with a $14 \mathrm{w}-$ $\% \mathrm{HNO}_{3}$ solution. The dilution ratio in these cases was $100 \mathrm{~g}$ of $\mathrm{HNO}_{3}$ per one gram of original 
slurry in the sample. After this acid dilution stage, the analysis procedure was the same as for the standard $\mathrm{Na}$ analyses described above.

Particle size distributions (PSD) of the original slurries and the samples taken during the experiments were measured with a Malvern Mastersizer 3000 laser diffraction particle size analyzer. The particle size analyses were performed without sonication and without dispersing agents, at a constant stirring rate of $3000 \mathrm{rpm}$. The range of measurement, according to the manufacturer, was 0.01 to $3500 \mu \mathrm{m}$. Each sample was measured five times, and the analyzer calculated the average PSD automatically.

Table 1. Characteristics of bauxite residue slurries.

\begin{tabular}{lllllllll}
\hline Slurry & $\begin{array}{l}\mathrm{pH} \\
(-)\end{array}$ & $\begin{array}{l}\mathrm{TS}^{*} \\
(\mathrm{~g} / \mathrm{kg})\end{array}$ & $\begin{array}{l}\mathrm{TDS}^{* *} \\
(\mathrm{~g} / \mathrm{kg})\end{array}$ & $\begin{array}{l}\text { Density } \\
\left(\mathrm{kg} / \mathrm{m}^{3}\right)\end{array}$ & $\begin{array}{l}\mathrm{C}_{\mathrm{Na}}{ }^{* * *} \\
(\mathrm{~g} / \mathrm{kg})\end{array}$ & $\begin{array}{l}\mathrm{D}_{10} \\
(\mu \mathrm{m})\end{array}$ & $\begin{array}{l}\mathrm{D}_{50} \\
(\mu \mathrm{m})\end{array}$ & $\begin{array}{l}\mathrm{D}_{90} \\
(\mu \mathrm{m})\end{array}$ \\
\hline Slurry I & 13.20 & 442 & 52 & 1363 & 27.2 & 0.87 & 6.9 & 235 \\
Slurry II & 12.92 & 330 & 8 & 1290 & 2.3 & 0.90 & 2.6 & 17 \\
Slurry III & 13.46 & 483 & 86 & 1450 & 33.3 & 0.90 & 3.9 & 27 \\
\hline
\end{tabular}

${ }^{*}$ Total solids in slurry

${ }^{* *}$ Total dissolved solids in the liquid phase of slurry

${ }^{* * *}$ Concentration of $\mathrm{Na}$ in the liquid phase of slurry

The elemental composition of the slurry was measured with a Jeol JSM-5800 SEM-EDS (scanning electron microscope with an energy-dispersive x-ray spectrometer). Prior to SEM-EDS analyses, the slurry samples were dried in an oven to obtain solid residues consisting of all suspended and dissolved solids present in the slurry. Each sample was analyzed at several different locations, and the average concentrations of each element were calculated. The results of the SEM-EDS analyses are shown in Table 2. It can be seen in Table 2 that the titanium content of Slurry I is significantly higher than that of Slurries II and III, whereas the iron content of Slurry I is correspondingly lower. Moreover, Slurry II has the lowest sodium content but the highest concentration of calcium. The mineralogical compositions of several different bauxite residues, analyzed by XRF, have been reported in the literature, for instance by Gräfe et al. (2011).

Table 2. Average elemental composition of bauxite residue slurries.

\begin{tabular}{lllllllll}
\hline Slurry & $\begin{array}{l}\mathrm{C} \\
(\mathrm{w}-\%)\end{array}$ & $\begin{array}{l}\mathrm{O} \\
(\mathrm{w}-\%)\end{array}$ & $\begin{array}{l}\mathrm{Na} \\
(\mathrm{w}-\%)\end{array}$ & $\begin{array}{l}\mathrm{Al} \\
(\mathrm{w}-\%)\end{array}$ & $\begin{array}{l}\mathrm{Si} \\
(\mathrm{w}-\%)\end{array}$ & $\begin{array}{l}\mathrm{Ca} \\
(\mathrm{w}-\%)\end{array}$ & $\begin{array}{l}\mathrm{Ti} \\
(\mathrm{w}-\%)\end{array}$ & $\begin{array}{l}\mathrm{Fe} \\
(\mathrm{w}-\%)\end{array}$ \\
\hline Slurry I & 1 & 39 & 11 & 10 & 5 & 1 & 10 & 23 \\
Slurry II & 1 & 39 & 8 & 10 & 7 & 4 & 3 & 28 \\
Slurry III & 1 & 37 & 11 & 13 & 7 & 1 & 3 & 27 \\
\hline
\end{tabular}

\subsection{Experiments and equipment}

Grinding experiments were carried out by using a Retsch PM 100 planetary ball mill and a constant rotation speed of $400 \mathrm{rpm}$. The total grinding times were 1 and $10 \mathrm{~min}$, and the volume of each batch was $120 \mathrm{~mL}$. Steel balls $(\mathrm{D}=10 \mathrm{~mm})$ were used as the grinding medium to break the particle flocs. The mass of steel balls was constant $173 \mathrm{~g}$ in all cases, corresponding to $89-100 \%$ of the 
mass of the slurry, depending on the density of each slurry (Table 1). The dimensions of the grinding vessel are shown in Fig. 1.

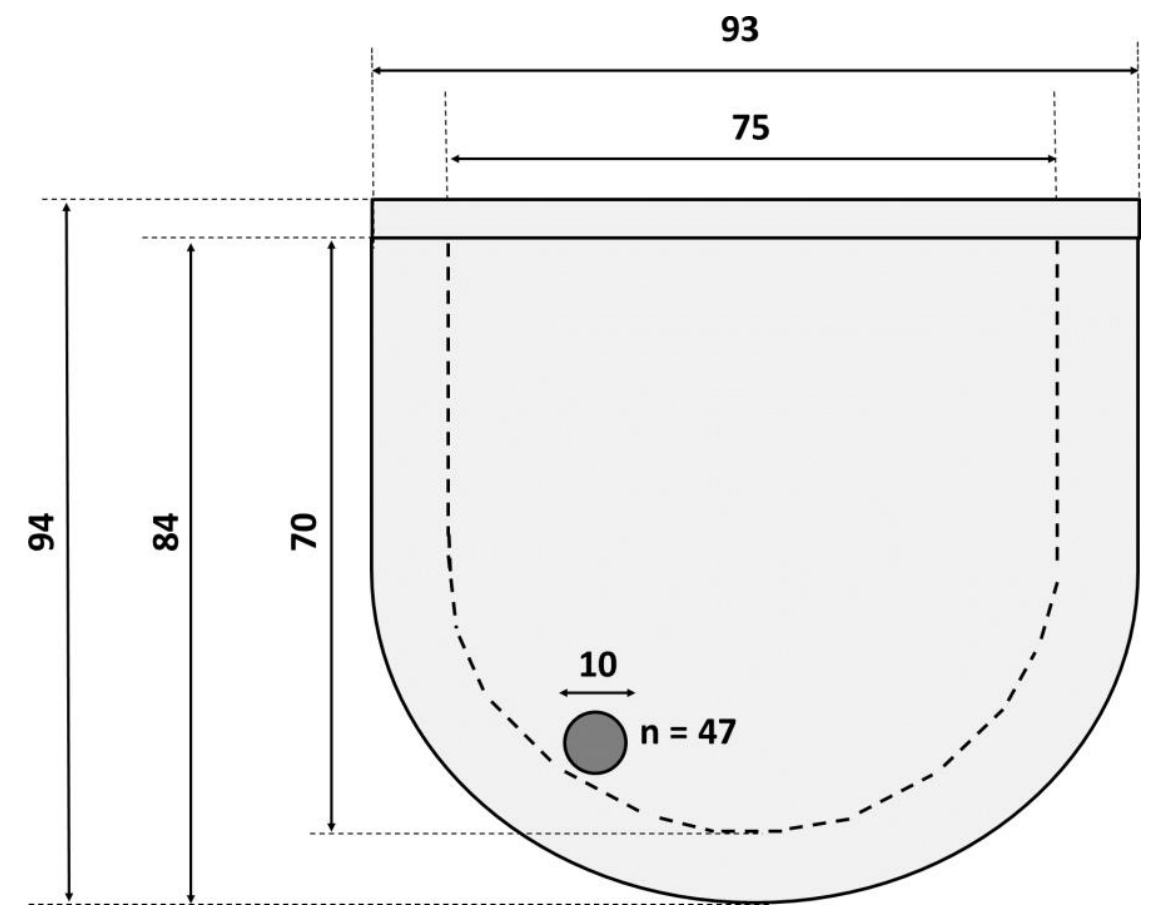

Fig. 1. Dimensions of the grinding vessel of the planetary ball mill (in millimeters).

The experiments were performed according to the experimental plan presented in Fig. 2. Four different weight-based dilution ratios between 0:1 and 10:1 were used at $22{ }^{\circ} \mathrm{C}$. Reverse osmosis quality Millipore water was used for the dilution. After the dilution, the samples were shaken and allowed to stabilize in closed bottles for 24 hours. The samples were then ground in the planetary ball mill for $1 \mathrm{~min}$, and after sampling the grinding was continued for 9 min. As can be seen in Fig. 2, twelve different samples were collected from the experimental sequence with each slurry. The samples were taken from a manually agitated suspension with a Pasteur pipette. All samples were then analyzed for particle size distribution and sodium content. 


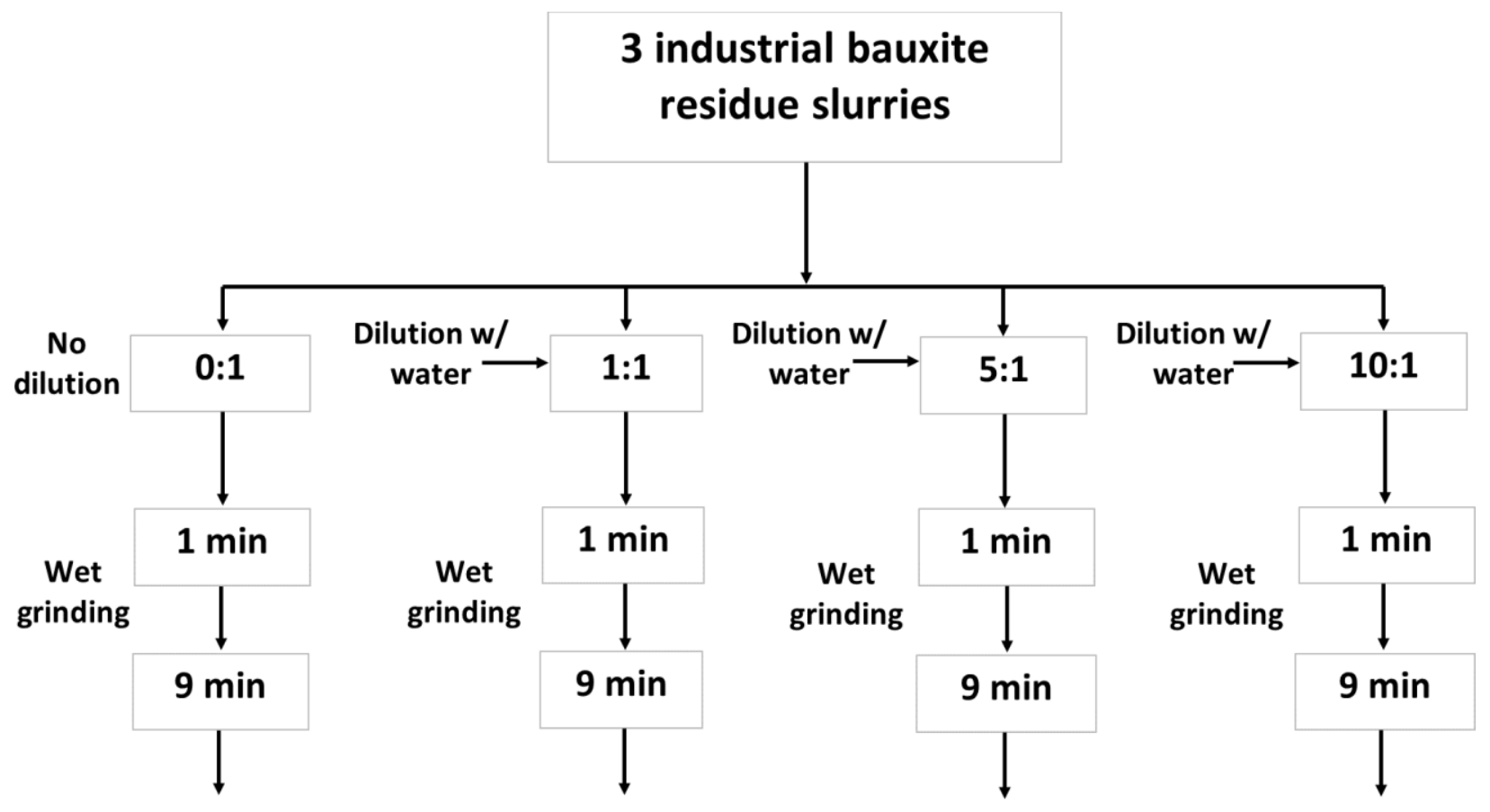

Fig. 2. Experimental plan including dilution and grinding operations.

In addition to the leaching and grinding experiments, the $\mathrm{pH}$ of the slurries with and without the presence of solids was investigated. Clear filtrates were produced from each slurry by filtering the slurry through Whatman 42 filter paper. Five grams of slurry or filtrate was then diluted with water for several times, to obtain a final L/S ratio of 1000. After each dilution step, the samples were shaken and allowed to stabilize for 15 minutes before measuring the $\mathrm{pH}$.

\subsection{Calculations and definitions}

The L/S ratio used in this study is defined as the ratio of the dilution water and the slurry. It has to be noted here that the L/S ratio in this case does not refer to the liquid/solids ratio, which is more typically used in the literature.

$L / S$ ratio $=\frac{m_{\text {dilution water }}}{m_{\text {slurry }}}$

where $m_{\text {dilution water }}(\mathrm{kg})$ is the mass of the pure water used for dilution of the slurry and $m_{\text {slurry }}(\mathrm{kg})$ is the mass of the original slurry.

The dilution factor $D F$ for the liquid phase of the slurry is 


$$
D F=\frac{(L / S \text { ratio })+\frac{m_{\text {motherliquor }}}{m_{\text {slurry }}}}{\frac{m_{\text {motherliquor }}}{m_{\text {slurry }}}}
$$

The amount of dissolved sodium relative to the amount of mother liquor $c_{N a}$, relative, i.e. the relative concentration of $\mathrm{Na}(\mathrm{kg} / \mathrm{kg})$ is defined as

$c_{\text {Na,relative }}=D F \cdot c_{N a, \text { sample }}$

where $c_{\mathrm{N} a \text {,sample }}(\mathrm{kg} / \mathrm{kg})$ is the concentration of sodium in the liquid phase of the slurry after dilution.

The results of thermometric titration are discussed below with respect to the total caustic and total soda contents of the liquid samples. The total caustic is defined as the total hydroxyl ion content comprising 1) the free hydroxyl ion content and 2) one mol hydroxyl ion per mol aluminate. The term Caustic in Tables 5 and 6 refers to the total caustic. Total soda is defined as the sum of total caustic content and the carbonate content of the liquid.

\section{Results and discussion}

The results are discussed with respect to the solid and liquid phases of the slurries, including particle size distributions, $\mathrm{pH}$ and concentration of dissolved compounds. Dissolution is not the only mechanism which may change the state of the slurry: desorption of adsorbed compounds, as well as various exchange reactions, may also take place. However, to simplify the discussion, "dissolution" is used as a collective term to describe the above-mentioned phenomena in this paper.

\subsection{Particle size distributions}

The particle size distribution in each bauxite residue slurry was measured in order to understand how much the dilution and the grinding of the samples affect the size of the solids. The bauxite residue solids consist of flocs formed with the help of polymer addition in the washing/thickening stage, but it is unclear how much grinding is required to break these flocs to primary particles. Therefore, quite a great number of samples was analyzed for the particle size. Four samples of different dilution ratios were prepared from each slurry, and the maximum grinding time was 10 minutes. The results are shown in Fig. 3.

As shown in Fig. 3a, 3d, and 3g, the particle size distributions of the original slurries were quite different. Slurry I contained a more significant proportion of large particles, whereas Slurries IIIII had hardly any particles larger than $100 \mu \mathrm{m}$. The shape of each distribution was also unique, varying from relatively irregular (Slurry I) to a monomodal and almost symmetrical distribution in Slurry II. 
Before paying special attention to the effects of grinding, the influence of dilution ratio on the particle size distributions of the slurries are discussed. When the slurry samples were diluted with extra water, the size of particles in Slurries II and III did not change to a measurable extent (Fig. $3 \mathrm{~d}$ and $3 \mathrm{~g}$ ). However, the solids in Slurry I may have been affected slightly by the addition of water (Fig. 3a). However, this observation can possibly be explained by a sampling error, which arises from the fact that the probability of a large particle to end up in the sample decreases sharply when the same number of particles are suspended in increasing volumes of liquid. Additionally, the settling velocity of the coarse particles is increased when the settling is less hindered by other particles, which may make it more difficult to obtain a representative sample. For instance, the non-hindered settling velocity for the largest particles in Slurry I was a couple of centimeters per second, whereas the settling velocity of $100 \mu \mathrm{m}$ particles was lower than 1 millimeter per second.

The grinding time, on the other hand, had a clearer influence on the particle size distributions. Irrespective of the slurry, the distribution evolved towards more monomodal and became narrower when the grinding was continued. After 1 minute of grinding with the planetary ball mill, the large end peak had disappeared from the distribution of Slurry I (Fig. 3b), and after 10 minutes, particles larger than $50 \mu \mathrm{m}$ did practically not exist in the slurry any longer (Fig. 3c). The shape of particle size distribution of Slurry II was less clearly reduced by the grinding (Fig. 3d-f). However, the size of particles was reduced to such an extent that the peak became clearly higher and the distribution narrower. The use of a high L/S ratio seems to have increased the peak height of the distribution slightly (Fig. 3e and 3f). In the case of Slurry III (Fig. 3 g-i), the particle size reduction was clearly observable only after 10 minutes of grinding, when the bimodal distribution became unambiguously monomodal.

The role of desilication products in particle size distribution can be notable. It has been reported that desilication products usually exist both as separate particles and as components in flocs with other particles. In a previous study of Picaro et al. (2002), a very clear reduction of particles at a relatively narrow particle size range $(0.8$ to $10 \mu \mathrm{m})$ was obtained by sulfuric acid leaching, which was shown to be due to the dissolution of desilication products. On the basis of Fig. 3, it is easy to conclude that such dissolution is not very significant when leaching is performed with increasing quantities of water, without the presence of acid. 

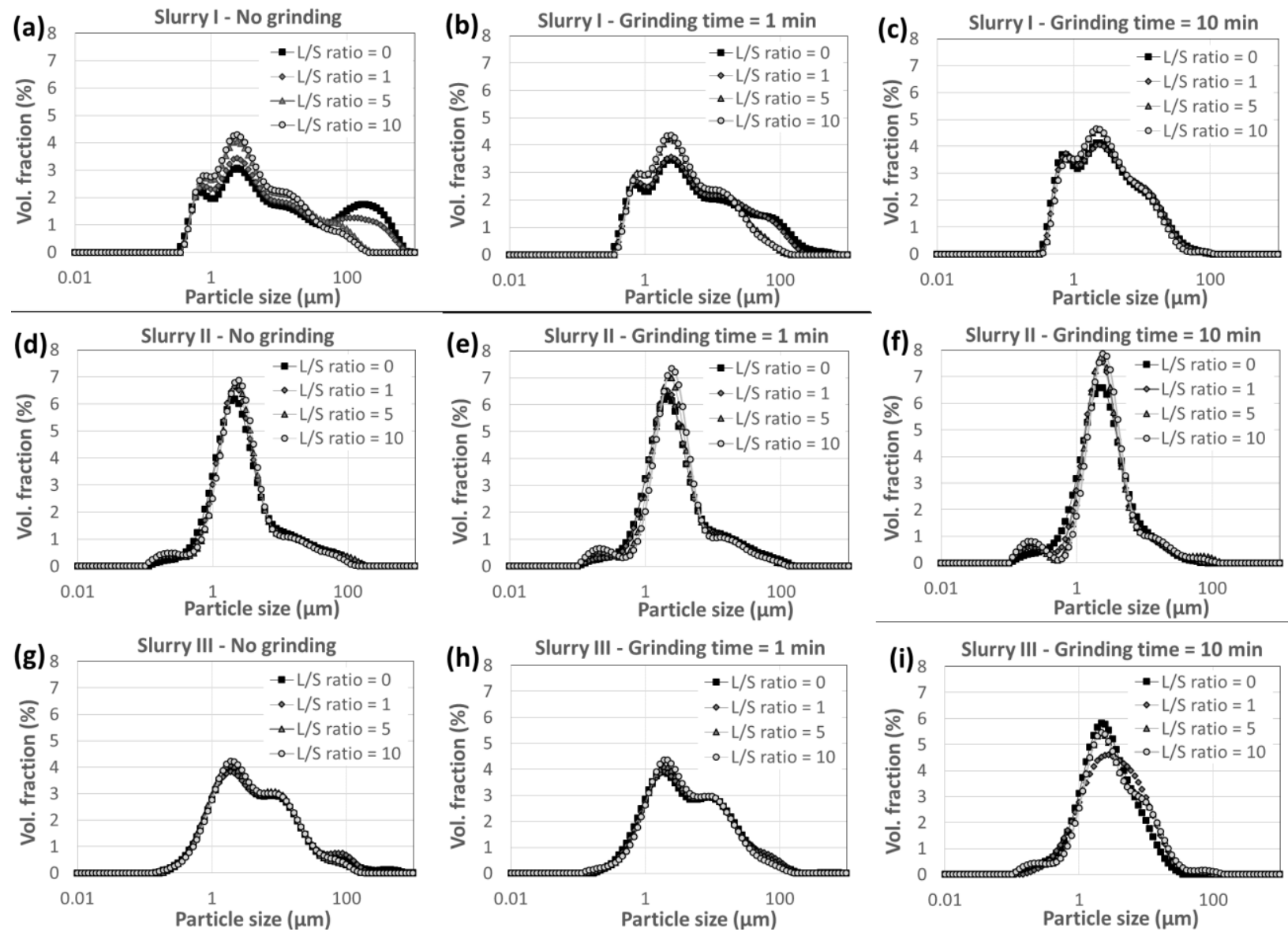

Fig. 3. Particle size distributions of the solids for the three slurries, obtained with different L/S ratios and grinding times.

To summarize the experiments related to particle size, the 10 min grinding time had a clearly observable influence on the PSD in all cases: the width of the PSD was significantly reduced and coarse particles were affected more than fine ones.

\subsection{Reduction of $\mathrm{pH}$}

The reduction of the $\mathrm{pH}$ is possibly the most important effect when a bauxite slurry is diluted with water. It is important to be aware of changes in the $\mathrm{pH}$, because it has great influence on the dissolution of alkali and metals from the residue. Bauxite residues have been observed to have significant acid neutralizing capacity (Johnston et al., 2010), which makes the reduction of $\mathrm{pH}$ challenging in practice. Alkaline material from red mud has been reported to leach out from bauxite residue at reduced $\mathrm{pH}$ (Sahu et al., 2010).

The aim of the $\mathrm{pH}$ measurements was to evaluate whether the presence of solids may have an influence on the $\mathrm{pH}$ during dilution with water, i.e. whether the liberation of caustic components from the solid phase may prevent $\mathrm{pH}$ reduction. Table 3 sums up the initial situation before the addition of water. 
Table 3. Properties of the slurry (S) and filtrate (F) samples with respect to the mass of liquid and solids, and the initial $\mathrm{pH}$ prior to dilution of the sample with water.

\begin{tabular}{lllllll}
\hline Sample & $\begin{array}{l}\text { Mass of } \\
\text { sample } \\
(\mathrm{g})\end{array}$ & $\begin{array}{l}\text { Mass of } \\
\text { liquid } \\
(\mathrm{g})\end{array}$ & $\begin{array}{l}\text { Mass of } \\
\text { water } \\
(\mathrm{g})\end{array}$ & $\begin{array}{l}\text { Mass of } \\
\text { total solids } \\
(\mathrm{g})\end{array}$ & $\begin{array}{l}\text { Mass of } \\
\text { dissolved solids } \\
(\mathrm{g})\end{array}$ & $\begin{array}{l}\text { Initial } \mathrm{pH} \\
(-)\end{array}$ \\
\hline $\mathrm{S}(\mathrm{I})$ & 5.0 & 2.94 & 2.79 & 2.21 & 0.15 & 13.20 \\
$\mathrm{~F}(\mathrm{I})$ & 5.0 & 5.0 & 4.74 & 0.26 & 0.26 & 13.20 \\
$\mathrm{~S}(\mathrm{II})$ & 5.0 & 3.38 & 3.35 & 1.65 & 0.03 & 12.97 \\
$\mathrm{~F}(\mathrm{II})$ & 5.0 & 5.0 & 4.96 & 0.04 & 0.04 & 12.97 \\
$\mathrm{~S}(\mathrm{III})$ & 5.0 & 2.83 & 2.59 & 2.42 & 0.24 & 13.23 \\
$\mathrm{~F}(\mathrm{III})$ & 5.0 & 5.0 & 4.57 & 0.43 & 0.43 & 13.23 \\
\hline
\end{tabular}

The reduction of $\mathrm{pH}$ with an increasing dilution factor, with and without the presence of solid particles, is shown in Fig. 4, where it is clear that the buffering capacity of bauxite residues is most essentially related to the alkaline components present in the liquid phase. Fig. 4a shows the actual $\mathrm{pH}$ data for dilution factors ranging from 0 to 1000. In order to improve the clarity of the data obtained for low dilution ratios, logarithmic scale is used on the $\mathrm{x}$-axis in Fig. 4b.

Generally, regarding the $\mathrm{pH}$ of the diluted samples, there was not much difference between the slurry and the suspended solids free filtrate. However, some interesting observations were made concerning the effect of the presence of solids during the dilution procedure. Slurry I was not influenced by the presence of solids, while in the case of Slurry II, the presence of solid particles increased the $\mathrm{pH}$ slightly. On the other hand, the $\mathrm{pH}$ of Slurry III was slightly lower when suspended solids were present.
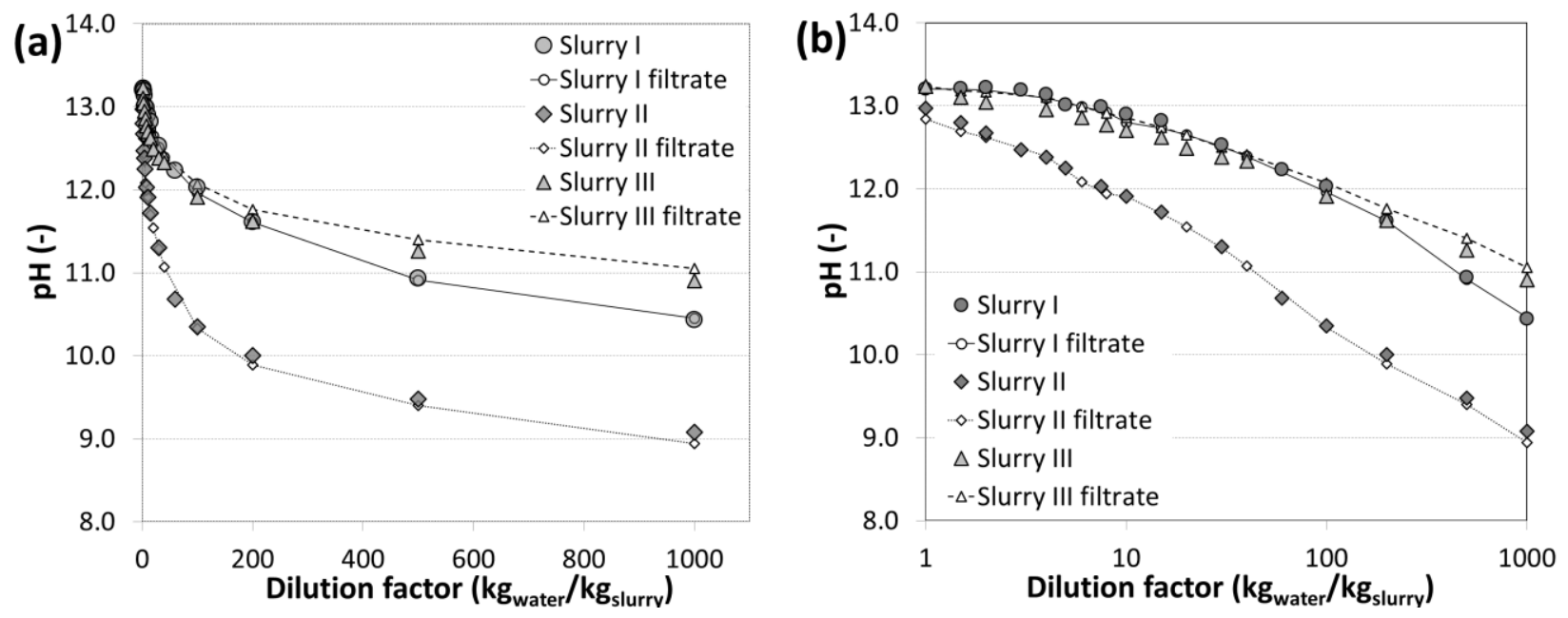

Fig. 4. The dependence of the $\mathrm{pH}$ of each slurry on the dilution factor, with and without suspended solids: original data (a), and data plotted with logarithmic scale of the $\mathrm{x}$-axis (b).

Comparison between the properties presented in Table 3 and the graphs presented in Fig. 4a-b reveals that the reduction of the $\mathrm{pH}$ was clearly dependent on the initial $\mathrm{pH}$ and the dissolved solids 
contents of the samples. The $\mathrm{pH}$ of Slurry II was most significantly reduced as a result of dilution, which was due to the low initial concentration of dissolved solids in the samples (Table 3).

It is likely that the presence of suspended solids would have had a clear effect on the pH (Fig. 4) if the measurements had been performed after a long storage time of the samples. The $\mathrm{pH}$ rebound is a well-known phenomenon taking place when such buffering solids are diluted with water. In this case, however, the $\mathrm{pH}$ measurement was started immediately after the dilution and finished when the $\mathrm{pH}$ meter showed a stable value. The time required for the stabilization of the $\mathrm{pH}$ electrode was typically $10 \mathrm{~min}$.

\subsection{Dissolution of sodium}

Dissolution of sodium from bauxite residues at various L/S ratios was investigated by using two alternative methods to see how important a role the $\mathrm{pH}$ plays in the process. Section 4.3.1 introduces the results obtained when the samples were centrifuged to remove the suspended solids prior to analysis, and Section 4.3.2 presents the results for samples which were diluted in acid before removing the solids by centrifugation.

\subsubsection{Dissolution in water}

Dissolution of the bauxite residue slurries in water at different L/S ratios appears to be straightforward and easy to predict in most cases. Figs. 5a and 5b show clearly that the liquid phase of the sample is mainly responsible for providing the water-soluble sodium under the applied conditions. Keeping in mind that in this paper the L/S ratio is defined as the ratio of added water and slurry, the results presented in Fig. 5a cannot provide unambiguous information about the dilution of the liquid phase of the slurry. Therefore, the mass of the mother liquor (ML) in the slurries was calculated, the true dilution factors for the mother liquor were calculated by using Eq. (2), and the obtained relative sodium concentrations $\left(\mathrm{g}_{\mathrm{Na}} / \mathrm{kg}_{\mathrm{ML}}\right)$, calculated by using Eq. (3), were plotted as a function of the L/S ratio (Fig. 5b).

Fig. 5b illustrates whether the dissolved $\mathrm{Na}$ originates from the mother liquor of from the suspended solids. In the case of Slurries I and III, dissolution of $\mathrm{Na}$ from the solids does not seem to play an important role, whereas the solid phase of Slurry II seems to be partially dissolved: the relative $\mathrm{Na}$ concentration is increased by $54 \%$. This result is somehow supported by the PSD presented in Fig. 3d-f, where the peak height of the PSD becomes higher and the fine end seems to become even finer as the $\mathrm{L} / \mathrm{S}$ ratio is increased. The main reason for the dissolution of suspended solids is most probably the reduction in the $\mathrm{pH}$ (Fig. 4a-b), which is the most significant in the case of Slurry II. At the maximum applied L/S ratio (10), the $\mathrm{pH}$ of Slurries I and III is reduced by approximately 0.3 and 0.5 , respectively, while the corresponding reduction in the $\mathrm{pH}$ of Slurry II is higher than 1. It is possible that the dissolved sodium was actually obtained by desorption mechanism from the surface of the solids, even though the phenomenon is referred to as dissolution above. 

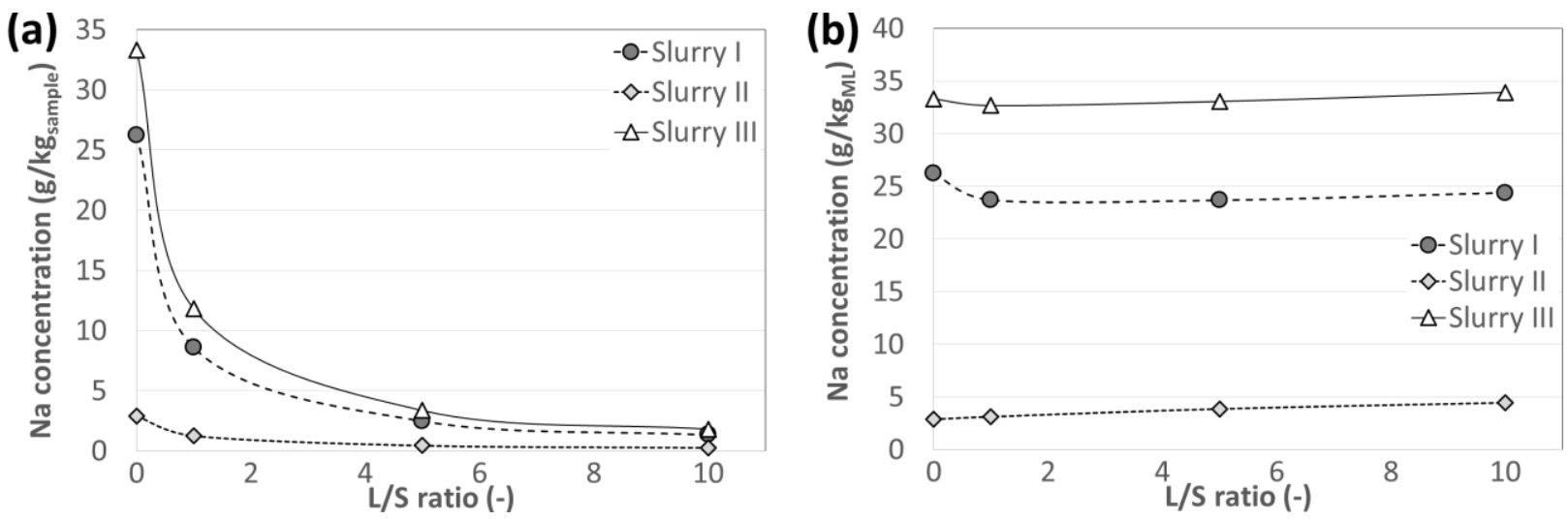

Fig. 5. Sodium concentrations in the liquid phase of the diluted slurries (a), and the same concentrations calculated with relation to the mass of the original liquid (mother liquor $=$ $\mathrm{ML}$ ) in the slurries (b).

\subsubsection{Dissolution in acid}

The concentrations of dissolved sodium in the samples prepared by using $14 \% \mathrm{HNO}_{3}$, measured similarly as above (Section 4.3.1), are presented for various L/S ratios in Fig. 6a. Figure 6b shows the same results calculated with relation to the mass of the mother liquor in the slurries. Comparison between Figs. 5 and 6 reveals that significant amounts of sodium are dissolved from the suspended solids when the $\mathrm{pH}$ of the sample is reduced to below 1 with nitric acid. It is clear that such significant amounts of sodium cannot be liberated only by removing the adsorbed $\mathrm{Na}$ from the particle surfaces: dissolution of the primary solid matrix has to occur as well.
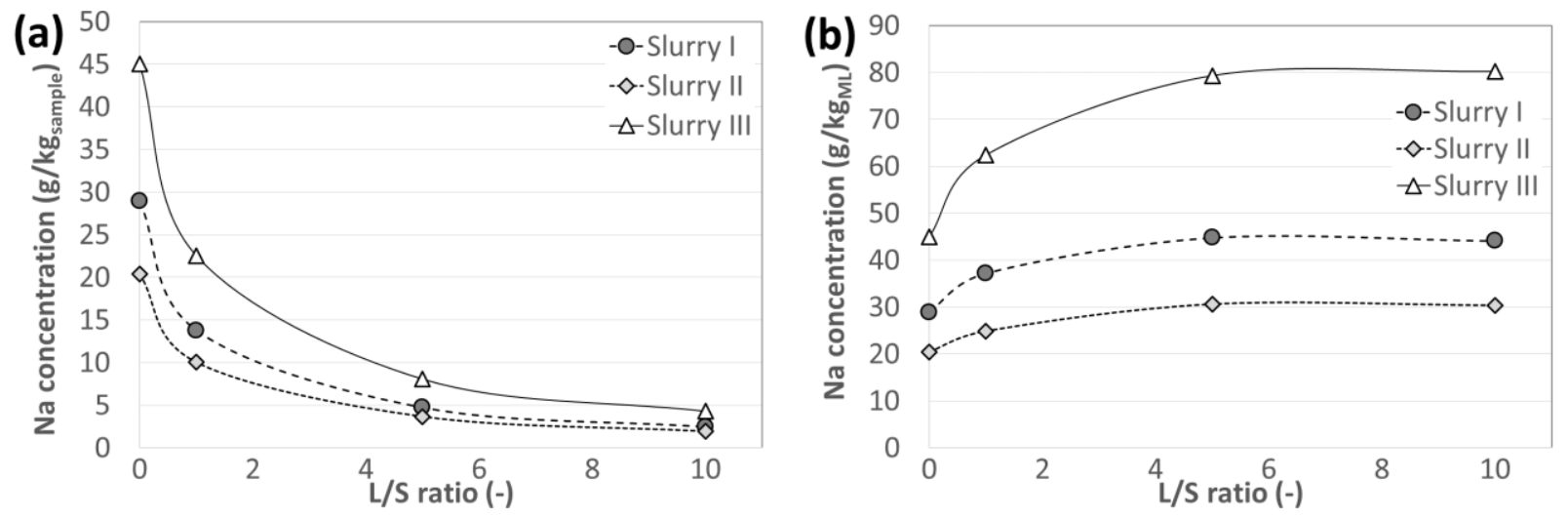

Fig. 6. Sodium concentrations in the liquid phase of the diluted slurries (a), and the same concentrations calculated with relation to the mass of the original liquid (mother liquor $=$ ML) in the slurries (b), when the samples have been digested with $\mathrm{HNO}_{3}$ prior to analysis.

When a bauxite residue slurry is diluted with an acidic solution, the buffering solids dissolve gradually with the $\mathrm{pH}$ reduction. The buffering alkaline solids are most typically certain hydroxides, carbonates, aluminates, and aluminosilicates (Gräfe et al., 2011; Ruyters et al., 2011). Some of the alkaline solids also liberate sodium to the liquid. These sources of Na include for 
instance natron-decahydrate, hydroxysodalite, and cancrinite (Gräfe et al., 2011). As mentioned above, the desilication products are well soluble in acid and contain both sodium and aluminum. The formation of a typical desilication product, Bayer sodalite, in the Bayer process can be described by Eq. (1), obtained from Smith (2009).

$$
6 \mathrm{Na}_{2} \mathrm{SiO}_{3}+6 \mathrm{NaAl}(\mathrm{OH})_{4}+\mathrm{Na}_{2} \mathrm{X} \rightarrow \mathrm{Na}_{6}\left[\mathrm{Al}_{6} \mathrm{Si}_{6} \mathrm{O}_{24}\right] \cdot \mathrm{Na}_{2} \mathrm{X}+12 \mathrm{NaOH}+6 \mathrm{H}_{2} \mathrm{O}
$$

where $X$ is an inorganic anion.

The observations regarding the dissolution of $\mathrm{Na}$ when the sample was prepared for analysis with acid can probably be associated with the dissolution of sodalite (Snars and Gilkes, 2009). A recent study of Rubinos and Barral (2013) shows that the dissolution of sodium from bauxite residue solids may increase very dramatically when the $\mathrm{pH}$ is reduced: the amount of dissolved $\mathrm{Na}$ increased from about $2000 \mathrm{mg}_{\mathrm{Na}} / \mathrm{kg}_{\text {solids }}$ at $\mathrm{pH} 9$ to over $20000 \mathrm{mg}_{\mathrm{Na}} / \mathrm{kg}_{\text {solids }}$ at $\mathrm{pH} 6$.

A general conclusion from the sodium dissolution experiments is that leaching with water alone is not always effective at recovering sodium from the solid phase of bauxite residue slurries. Dilution of the slurry samples with a nitric acid solution showed that considerable amounts of sodium can be readily recovered at room temperature. However, there are two important questions which have not been discussed so far:

1) Is there readily liberable sodium trapped inside the particle structures?

2) Does the dissolved sodium originate from caustic compounds?

The answer to the former question is sought in Sections 4.3.3, and the latter question is dealt with in Section 4.5.

\subsubsection{Influence of grinding}

One of the speculative assumptions in previous literature has been that sodium trapped within the pore structure of particle flocs could explain why the dissolution of sodium from bauxite residues is not always directly proportional to the quantity of mother liquor in the slurry. In order to examine whether this theory applies in the case of Slurries I-III, the slurry samples with various L/S ratios were ground with a planetary ball mill, and the sodium concentrations in the liquid were measured. The dimensionless sodium concentrations are presented in Fig. 7. 


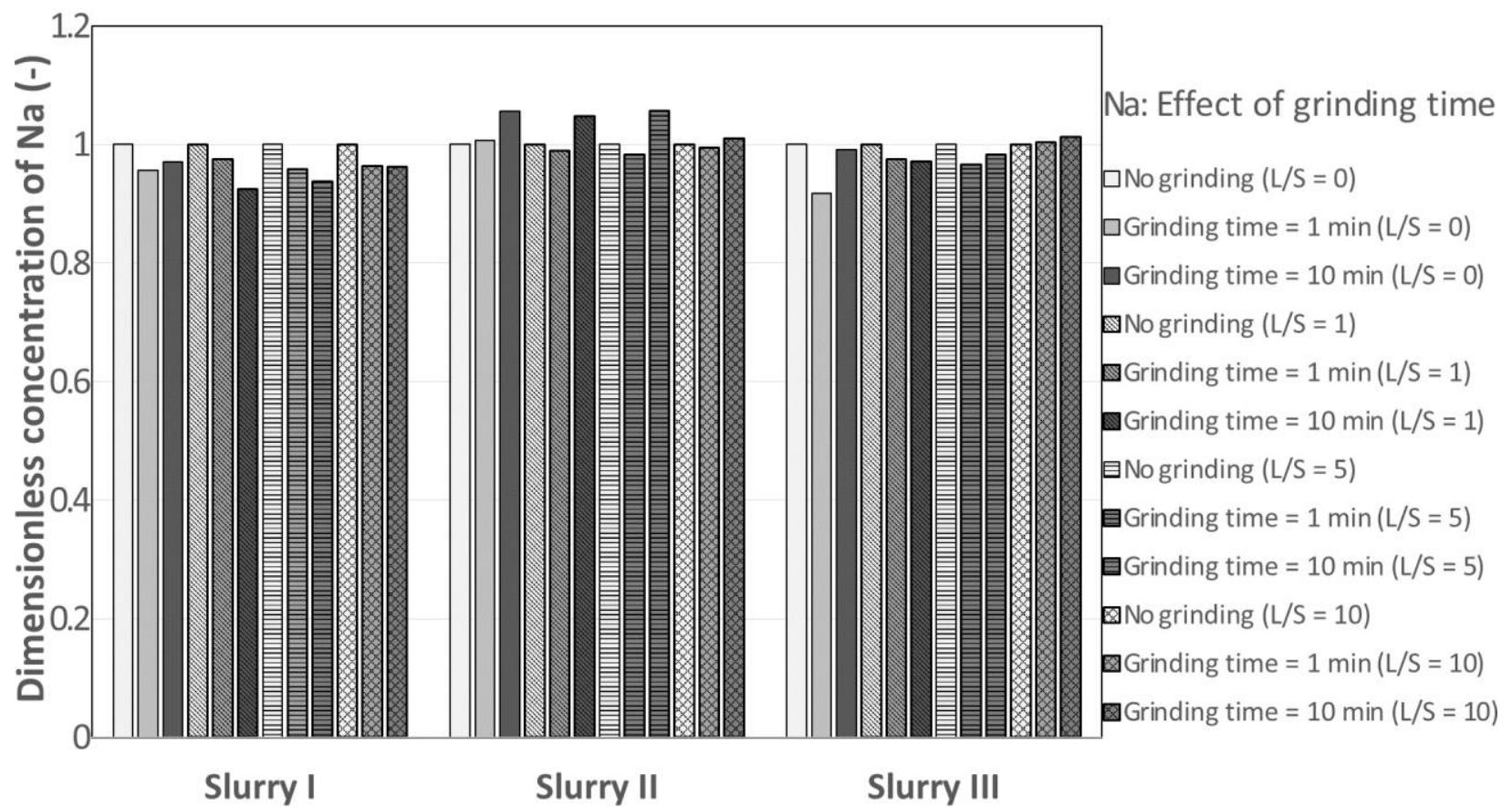

Fig. 7. The effect of grinding time on the dimensionless sodium ( $\mathrm{Na}$ ) concentration of the liquid phase of the slurries. Dimensionless sodium concentration means that the Na concentration of each non-ground sample is scaled to be 1 for all $\mathrm{L} / \mathrm{S}$ factors.

As Fig. 7 shows, grinding had practically no impact on the sodium concentrations of the liquid samples, which were taken after the slurries were allowed to cool down and stabilize at room temperature after grinding. Sampling from slurries warmed up by grinding could result in different observations. It is possible that the concentrations were slightly increased in the case of Slurry II, but those small differences have been more likely caused by normal inaccuracy of the sampling and analysis procedure. It is also unclear if some sodium was adsorbed into the solids of Slurries I and III due to grinding, or if the decrease in the Na concentrations was simply caused by the measurement error. In the future, it would be worth studying whether more effective fine grinding with other types of mills could change these conclusions.

\subsection{Dissolution of aluminum}

The dissolution of aluminum from bauxite residues may become a more important topic in the future, as stricter and stricter regulations aiming at improved material efficiency and waste minimization take effect. As for sodium above, the results presented below in Fig. 8a-b do not provide information about the exact origin of aluminum. In spite of this limitation, Fig. 8b shows clearly that $\mathrm{Al}$ is dissolved from the suspended solids of all slurries, and that the extent of dissolution depends on the applied L/S ratio. To recover the most easily soluble aluminum, the optimum L/S ratio for Slurries II and III seems to be approximately 5, while the result for Slurry I is relatively unclear. 

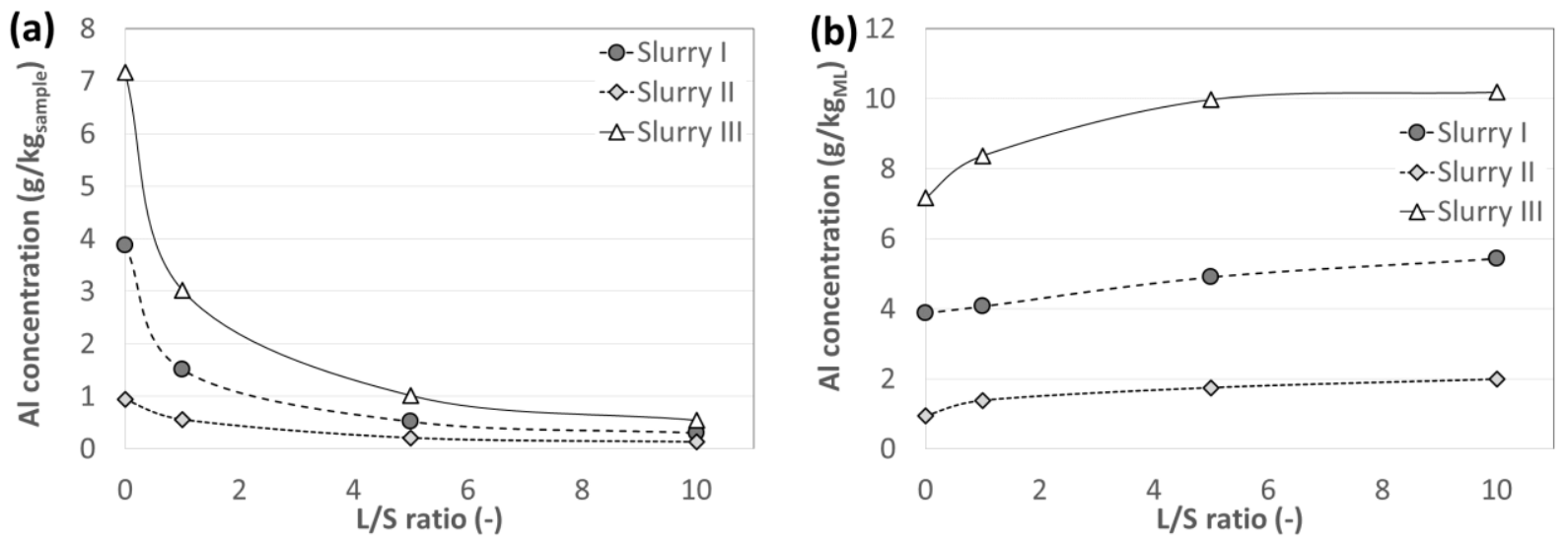

Fig. 8. Aluminum concentrations in the liquid phase of the diluted slurries (a), and the same concentrations calculated with relation to the mass of the original liquid (mother liquor $=$ $\mathrm{ML}$ ) in the slurries (b).

When comparing Fig. 8b with Fig. 5b, it is apparent that the ratio of dissolved aluminum to dissolved sodium is not constant as the L/S ratio is increased. A summary of the $\mathrm{Al} / \mathrm{Na}$ ratios, according to analyses with AAS, is presented in Table 4, where it can be seen that the influence of the $\mathrm{L} / \mathrm{S}$ ratio on the $\mathrm{Al} / \mathrm{Na}$ ratio is significant. When the $\mathrm{L} / \mathrm{S}$ ratio is increased from zero to ten, the $\mathrm{Al} / \mathrm{Na}$ ratios of Slurries I, II and III are increased by 51,44 , and $40 \%$, respectively. This result implies that the solids in the slurry contain proportionally more readily water-soluble aluminum compounds than water-soluble sodium compounds at the experimental conditions.

Table 4. Aluminum to sodium ratios $\left(c_{A l} / c_{N a}\right)$ for the liquid phase of the slurries at different $\mathrm{L} / \mathrm{S}$ ratios.

\begin{tabular}{lllll}
\hline & Al/Na ratio $(-)$ & & & \\
\cline { 2 - 5 } Slurry \# & $\mathrm{L} / \mathrm{S}^{*}=0$ & $\mathrm{~L} / \mathrm{S}=1$ & $\mathrm{~L} / \mathrm{S}=5$ & $\mathrm{~L} / \mathrm{S}=10$ \\
\hline Slurry I & 0.15 & 0.18 & 0.21 & 0.22 \\
Slurry II & 0.33 & 0.44 & 0.45 & 0.47 \\
Slurry III & 0.21 & 0.26 & 0.30 & 0.30 \\
\hline
\end{tabular}

* L/S means the mass ratio of added water and the original slurry.

\subsection{Dissolution of caustic compounds}

The dissolution of sodium and aluminum from bauxite residues was discussed above. Thermometric titration was applied to investigate how large a proportion of the total sodium is leached from the caustic compounds. The comparison of atomic absorption spectroscopy and thermometric titration presented in Fig. 9a-b provides useful information about the origin of sodium. Linear relationships for $\mathrm{N}_{2} \mathrm{O}$ contents determined with both techniques are presented for Slurries I and III in Fig 9a and for Slurry II in Fig. 9b. Fig. 9a shows excellent correlation coefficients for both slurries. Some data points had to be excluded from Fig. 9b, because the lowest 
measured concentrations were below the measurement range of the thermometric titrator, and therefore the results shown in Fig. $9 \mathrm{~b}$ do not enable definitive conclusions.
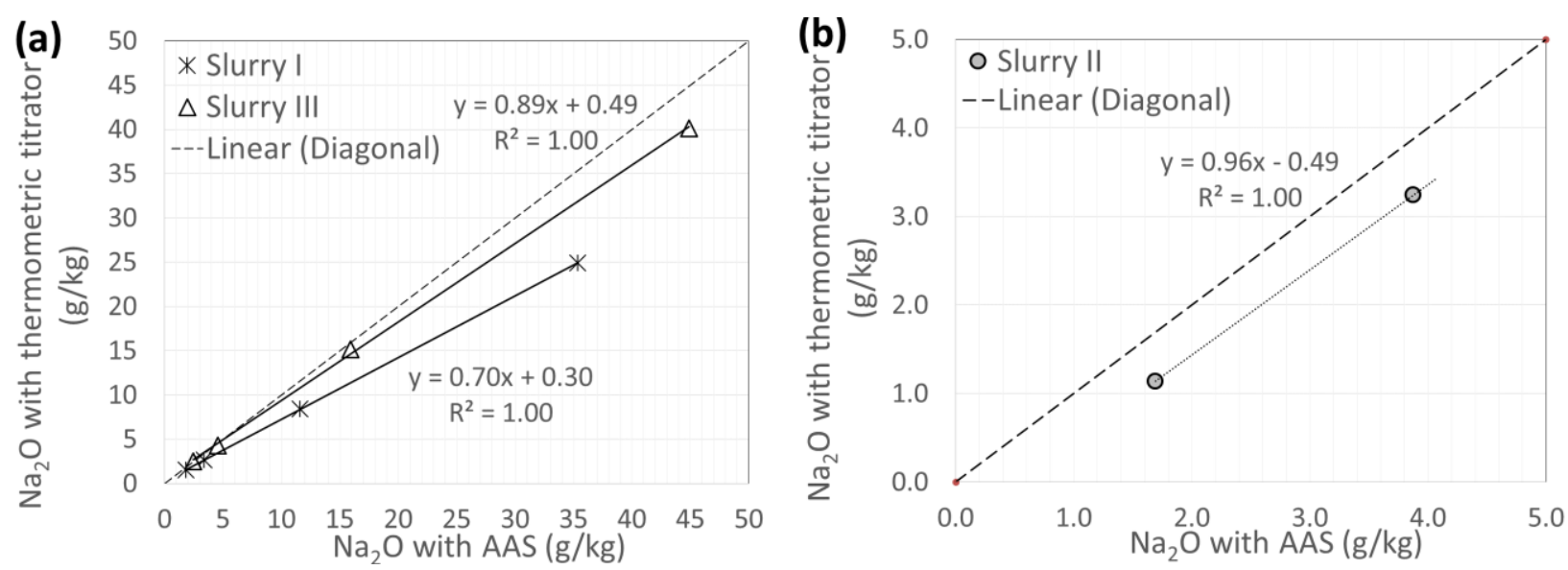

Fig. 9. Comparison of $\mathrm{Na}_{2} \mathrm{O}$ concentrations $\left(\mathrm{g}_{\mathrm{Na} 2} \mathrm{O} / \mathrm{kg}_{\text {liquid }}\right)$ measured with an atomic absorption spectrometer (AAS) and thermometric titrator for Slurries I and II (a) and Slurry II (b). The difference between the AAS results representing the total sodium (calculated as $\mathrm{Na}_{2} \mathrm{O}$ ) and the titration results representing total caustic concentration (calculated $\mathrm{as}_{\mathrm{Na}} \mathrm{O}$ ) indicates the source of $\mathrm{Na}$.

The results presented in Fig. 9 are interpreted further in Table 5, which presents the total caustic / total sodium ratios at different L/S ratios for each slurry. These results imply that the relative concentration of total caustic, i.e. the hydroxyl content to the sodium content, increased with the $\mathrm{L} / \mathrm{S}$ ratio in the case of Slurries I and III. However, it is not clear how important a role the $\mathrm{OH}$ groups originating from other sources than compounds of sodium (e.g. $\mathrm{NaOH}$ ) play here. The high caustic / Na ratio obtained for Slurry III at the highest applied L/S ratio indicate quite clearly that caustic was dissolved from other metal hydroxides also. Because Slurry II could be analyzed for the total caustic only at two L/S ratios, it is impossible to make a distinct conclusion about that case. However, when the data presented above in Fig. 5b is compared with the caustic / Na ratios for Slurry II, it seems that the decreasing ratio can be logically explained by the observed dissolution behavior of $\mathrm{Na}$ from the solid phase.

Slurries I and II contained also carbonate, probably $\mathrm{Na}_{2} \mathrm{CO}_{3}$, although most samples of Slurry II showed carbonate contents below the lower measurement limit. The definition of total soda in Table 5 is: total soda $=$ total caustic + total carbonate. 
Table 5. The total caustic (titrated $\mathrm{OH}$ converted to $\mathrm{Na}_{2} \mathrm{O}$ ) to total $\mathrm{Na}_{2} \mathrm{O}$ (calculated from $\mathrm{Na}$ concentration measured with AAS) ratios for the liquid phase of the slurries at different L/S ratios. Additionally, the total soda to total $\mathrm{Na}_{2} \mathrm{O}$ ratios are shown in square brackets for samples where carbonate was detected. A missing value means that the concentration was below the measurement range of the titrator.

\begin{tabular}{lllll}
\hline & \multicolumn{4}{l}{ Caustic/ $\mathrm{Na}_{2} \mathrm{O}$ ratio $(-),\left[\right.$ Soda/ $\mathrm{Na}_{2} \mathrm{O}$ ratio $\left.(-)\right]$} \\
\cline { 2 - 5 } Slurry \# & $\mathrm{L} / \mathrm{S}^{*}=0$ & $\mathrm{~L} / \mathrm{S}=1$ & $\mathrm{~L} / \mathrm{S}=5$ & $\mathrm{~L} / \mathrm{S}=10$ \\
\hline Slurry I & $0.70,[0.77]$ & $0.73,[0.79]$ & $0.79,[0.87]$ & $0.83,[0.91]$ \\
Slurry II & $0.84,[0.91]$ & 0.67 & - & - \\
Slurry III & 0.89 & 0.95 & 0.95 & 1.0 \\
\hline
\end{tabular}

L/S means the mass ratio of added water and the original slurry.

Another interesting observation to be discussed is the behavior of aluminum in the dilution experiments. As concluded above from the AAS results presented in Table 4, the aluminum/sodium ratio increased with the dilution ratio. However, when the aluminum concentration determined by thermometric titration is investigated with relation to the caustic content (as $\mathrm{Na}_{2} \mathrm{O}$ ), the situation becomes different (Table 6). What can be observed by crosscomparison of Tables 4-6 is that the Al/caustic ratio (Table 6) remains practically constant (Slurry III) or increases slightly (Slurry I), which may be for the most part due to the same phenomenon related to the increasing proportion of caustic which can be observed in Table 5.

Table 6. Aluminum to total caustic ratios for Slurries I and III, determined by thermometric titration. The Al contents of Slurry II were below the measurement range of the device.

\begin{tabular}{|c|c|c|c|c|}
\hline \multirow[b]{2}{*}{ Slurry \# } & \multicolumn{4}{|c|}{$\mathrm{Al} /$ Caustic ratio (-) } \\
\hline & $\mathrm{L} / \mathrm{S}^{*}=0$ & $\mathrm{~L} / \mathrm{S}=1$ & $\mathrm{~L} / \mathrm{S}=5$ & $\mathrm{~L} / \mathrm{S}=10$ \\
\hline Slurry I & 0.14 & 0.15 & 0.18 & 0.17 \\
\hline Slurry III & 0.17 & 0.16 & 0.17 & 0.16 \\
\hline
\end{tabular}

L/S means the mass ratio of added water and the original slurry.

\section{Conclusions}

Dissolution of the two most abundantly available metals, sodium and aluminum, and total caustic, from three different bauxite residues was investigated by leaching experiments. The leaching behavior of sodium, aluminum and caustic from bauxite residues was observed to depend strongly on the applied L/S ratio. The dissolution phenomena seemed to be affected by the leaching conditions rather than by mechanical shear. This observation is in accordance with the results of Thornber and Binet (1999), who showed that the relative amount of sodium (expressed as $\mathrm{Na}_{2} \mathrm{O}$ ) adsorbed on the solids increases with the total alkali content of the liquid phase. The entrapment of soluble sodium within the particle flocs, as speculatively discussed in some previous papers, did not appear to have a significant influence on the liberation of $\mathrm{Na}$. However, mechanical 
treatment of the particles may have a significant influence on the kinetics of sodium dissolution, but this was not within the scope of this paper. The most important conclusion from this study is that the total amount of water-soluble alkali in bauxite residue slurries depends on the concentration of suspended solids and the process $\mathrm{pH}$, and varies with the composition of the slurry. The relative concentrations of total sodium, aluminum and caustic concentrations were also clearly influenced by the L/S ratio. Other factors, such as the composition of the leaching solution and the leaching temperature, are also of some importance, and should be studied in closer detail in the future. All these aspects should be taken into consideration when planning environmentally friendly methods for the disposal of bauxite residues.

\section{References}

Agatzini-Leonardou, S., Oustadakis, P., Tsakiridis, P.E., Markopoulos, Ch., 2008. Titanium leaching from red mud by diluted sulfuric acid at atmospheric pressure. J. Hazard. Mater. 157, 579-586.

Arslan, S., Demir, G.K., Celikel, B., Baygul, M., Suarez, C.E., 2012. ETI Aluminum red mud characterization and processing. In: Light Metals 2012. Edited by C.E. Suarez. TMS (The Minerals, Metals \& Materials Society). ISBN: 978-1-1182-9139-9

Atun, G., Hisarli, G., 2000. A study of surface properties of red mud by potentiometric method. J. Colloid Interface Sci. 228, 40-45.

Boger, D.V., 2012. Personal perspective on paste and thickened tailings: a decade on. Mining Technol. 121(1), 29-36.

Bonenfant, D., Kharoune, L., Sauve, S., Hausler, R., Niquette, P., Mimeault, M., Kharoune, M., 2008. $\mathrm{CO}_{2}$ sequestration by aqueous red mud carbonation at ambient pressure and temperature. Ind. Eng. Chem. Res. 47, 7617-7622.

Borges, A.J.P., Hauser-Davis, R.A., de Oliveira, T.F., 2011. Cleaner red mud residue production at an alumina plant by applying experimental design techniques in the filtration stage. J. Clean. Prod. 19, 1763-1769.

Brunori, C., Cremisini, C., Massanisso, P., Pinto, V., Torricelli, L., 2005. Reuse of a treated red mud bauxite waste: studies on environmental compatibility. J. Hazard. Mater. B117, 55-63.

Chvedov, D., Ostap, S., Le, T., 2001. Surface properties of red mud particles from potentiometric titration. Colloid. Surface. A. 182, 131-141.

Clifton, M., Nguyen, T., Frost, R., 2007. Effect of ionic surfactants on bauxite residues suspensions viscosity. J. Colloid Interface Sci. 307, 572-577. 
Cooling, D.J., 2007. Improving sustainability of residue management practices - Alcoa World Alumina Australia. Paste 2007 - A. Fourie and R.J. Jewell (eds). Australian centre for geomechanics, Perth, Australia.

Dilmore, R., Lu, P., Allen, D., Soong, Y., Hedges, S., Fu, J.K., Dobbs, C.L., Degalbo, A., Zhu, C., 2008. Sequestration of $\mathrm{CO}_{2}$ in mixtures of bauxite residue and saline wastewater. Energy Fuels 22, 343-353.

Fourie, A., 2009. Preventing catastrophic failures and mitigating environmental impacts of tailings storage facilities. Procedia Earth Planet. Sci. 1, 1067-1071.

Ghosh, I., Guha, S., Balasubramaniam, R., Kumar, A.V.R., 2011. Leaching of metals from fresh and sintered red mud. J. Hazard. Mater. 185, 662-668.

Gräfe, M., Power, G., Klauber, C., 2011. Bauxite residue issues: III. Alkalinity and associated chemistry. Hydrometallurgy. 108, 60-79.

Hamdy, M.K., Williams, F.S., 2001. Bacterial amelioration of bauxite residue waste of industrial alumina plants. J. Ind. Microbiol. Biotechnol. 27, 228-233.

He, H., Yue, Q., Qi, Y., Gao, B., Zhao, Y., Yu, H., Li, J., Li, Q., Wang, Y., 2012. The effect of incorporation of red mud on the properties of clay ceramic bodies. Appl. Clay Sci. 70, 67-73.

Hind, A.R., Bhargava, S.K., Grocott, S.C., 1999. The surface chemistry of Bayer process solids: a review. Colloid. Surface. A. 146, 359-374.

Jankovic, B., Smiciklas, I., Stajic-Trosic, J., Antonovic, D., 2013. Thermal characterization and kinetic analysis of non-isothermal decomposition process of Bauxite red mud. Estimation of density distribution function of the apparent activation energy. Int. J. Miner. Process. 123, 46-59.

Johnston, M., Clark, M.W., McMahon, P., Ward, N., 2010. Alkalinity conversion of bauxite refinery residues by neutralization. J. Hazard. Mater. 182, 710-715.

Kinnarinen, T., Lubieniecki, B., Helsto, J.-J., Häkkinen, A., 2012. Enabling economical dry stacking of bauxite residue by efficient deliquoring and washing with a membrane filter press. 19th International Symposium and Exhibition of ICSOBA-2012, Belém, Brazil, October 29 November 2, 2012.

Kinnarinen, T., Lubieniecki, B., Holliday, L., Helsto, J.-J., Häkkinen, A., 2015. Enabling safe dry cake disposal of bauxite residue by deliquoring and washing with a membrane filter press. Waste Manag. Res. 33(3), 258-266.

Kinnarinen, T., Lubieniecki, B., Holliday, L., Häkkinen, A., 2013. Filtration and washing of bauxide residue using a vertical filter press. ICSOBA-2013, Krasnoyarsk, Russia, September 3 6, 2013. 
Kirwan, L.J., 2009. A study of polyacrylate and hydroxamate co-dosing flocculation of stabilised bauxite residue material. Int. J. Miner. Process. 91, 28-33.

Kirwan, L.J., Hartshorn, A., McMonagle, J.B., Fleming, L., Funnell, D., 2013. Chemistry of bauxite residue neutralisation and aspects to implementation. Int. J. Miner. Process. 119, 40-50.

Kutle, A., Nad, K., Obhodas, J., Orescanin, V., Valkovic, V., 2004. Assessment of environmental condition in the waste disposal site of an ex-alumina plant near Obrovac, Croatia. X-Ray Spectrom. $33,39-45$.

Liu, W., Yang, J., Xiao, B., 2009. Review on treatment and utilization of bauxite residues in China. Int. J. Miner. Process. 93, 220-231.

Liu, Y., Lin, C., Wu, Y., 2007. Characterization of red mud derived from a combined Bayer Process and bauxite calcination method. J. Hazard. Mater. 146, 255-261.

Liu, Y., Naidu, R., Ming, H., 2013. Surface electrochemical properties of red mud (bauxite residue): Zeta potential and surface charge density. J. Colloid Interface Sci. 394, 451-457.

Mayes, W.M., Jarvis, A.P., Burke, I.T., Walton, M., Feigl, V., Klebercz, O., Gruiz, K., 2011. Dispersal and attenuation of trace contaminants downstream of the ajka bauxite residue (red mud) depository failure, Hungary. Environ. Sci. Technol. 45, 5147-5155.

Milacic, R., Zuliani, T., Scancar, J., 2012. Environmental impact of toxic elements in red mud studied by fractionation and speciation procedures. Sci. Total Environ. 426, 359-365.

Nguyen, Q.D., Boger, D.V., 1998. Application of rheology to solving tailings disposal problems. Int. J. Miner. Process. 54, 217-233.

Pejcinovic, N., Nguyen, T., Frost, R., 2007. Effect of surfactants on bauxite residues suspensions viscosity. Colloid. Surface A. 292, 21-26.

Picaro, T., Pei, B., Kane, A.R., 2002. Separation and mineralogical analysis of Bayer red mud. Dev. Chem. Eng. Mineral Process. 10(5/6), 475-489.

Pontikes, Y., Angelopoulos, G.N., 2013. Bauxite residue in cement and cementitious applications: Current status and a possible way forward. Resour. Conserv. Recycl. 73, 53-63.

Poulin, E., Blais, J.-F., Mercier, G., 2008. Transformation of red mud from aluminium industry into a coagulant for wastewater treatment. Hydrometallurgy. 92, 16-25.

Power, G., Gräfe, M., Klauber, C., 2011. Bauxite residue issues: I. Current management, disposal and storage practices. Hydrometallurgy. 108, 33-45.

Qu, Y., Lian, B., Mo, B., Liu, C., 2013. Bioleaching of heavy metals from red mud using Aspergillus niger. Hydrometallurgy 136, 71-77. 
Rubinos, D.A., Barral, M.T., 2013. Fractionation and mobility of metals in bauxite red mud. Environ. Sci. Pollut. Res. 20, 7787-7802.

Ruyters, S., Mertens, S., Vassilieva, E., Dehandschutter, B., Poffijn, A., Smolders, E., 2011. The red mud accident in Ajka (Hungary): Plant toxicity and trace metal bioavailability in red mud contaminated soil. Environ. Sci. Technol. 45, 1616-1622.

Sahu, R.C., Patel, R.K., Ray, B.C., 2010. Neutralization of red mud using $\mathrm{CO}_{2}$ sequestration cycle. J. Hazard. Mater. 179, 28-34.

Samal, S., Ray, A.K., Bandopadhyay, A., 2013. Proposal for resources, utilization and processes of red mud in India - a review. Int. J. Miner. Process. 118, 43-55.

Sidrak, Y.L., 1997. Control of the thickener operation in alumina production. Control Eng. Practice. 5(10), 1417-1426.

Smith, P., 2009. The processing of high silica bauxites - Review of existing and potential processes. Hydrometallurgy. 98, 162-176.

Snars, K., Gilkes, R.J., 2009. Evaluation of bauxite residues (red muds) of different origins for environmental applications. Appl. Clay Sci. 46, 13-20.

Thornber, M.R., Binet, D., 1999. Caustic soda adsorption on Bayer residues. In: Alumina, Worsley (Ed.), 5th International Alumina Quality Workshop. Bunbury, AQW Inc., pp. 498-507.

Vachon, P., Tyagi, R.D., Auclair, J.-C., Wilkinson, K.J., 1994. Chemical and biological leaching of aluminum from red mud. Environ. Sci. Technol. 28, 26-30.

Wang, S., Ang, H.M., Tade, M.O., 2008. Novel applications of red mud as coagulant, adsorbent and catalyst for environmentally benign processes. Chemosphere. 72, 1621-1635.

Zhang, N., Sun, H., Liu, X., Zhang, J., 2009. Early-age characteristics of red mud-coal gangue cementitious material. J. Hazard. Mater. 167, 927-932. 